Original Research Article

\title{
Standardization of ethanol addiction model in Swiss albino Mice
}

\author{
Tanvi M. Chotai*, Sarita M. Kapgate
}

Department of Agadtantra, Bharati Vidypeetha Deemed University College of Ayurveda, Pune, Maharashtra, India

Received: 30 April 2018

Accepted: 26 May 2018

*Correspondence to: Dr. Tanvi M. Chotai, Email: tanvichotai775@ gmail.com

Copyright: (C) the author(s), publisher and licensee Medip Academy. This is an openaccess article distributed under the terms of the Creative Commons Attribution NonCommercial License, which permits unrestricted noncommercial use, distribution, and reproduction in any medium, provided the original work is properly cited.

\begin{abstract}
Background: Addiction is compulsive need for use of a habit-forming substance. World Health Organization (WHO) reported that worldwide 3.3 million people died due to alcohol addiction in $2012-13$ and $11 \%$ of the population in India indulged in heavy drinking in 2014. Addiction is a prime socio-economical problem of society. Studying alcohol dependence in humans involved many ethical issues and experimental difficulties. Hence nonhuman animal experimental model has been used for a research on the topic of alcohol intoxication and dependence. Ethanol dependence has been preferred to develop in genetically modified strain of mice, C-57 which has a natural inclination to consume and develop addiction. But studying addiction in this special strain requires top end experimental facilities and financial aids. Authors reported the animal model to study ethanol dependence in Swiss albino mice. Aim of the study was to develop 'Ethanol Dependence in Swiss albino mice animal model' by intermitted access of $20 \%$ ethanol.

Methods: Dependence was developed in Swiss albino mice by intermitted access of $20 \%$ ethanol in two groups having six animals in each group. Dependence was confirmed by presence of the withdrawal symptoms like anxiety, muscular incoordination and behavioral changes of animals on abstinence of ethanol.

Results: Significant difference was noted on withdrawal symptoms, i.e. anxiety, muscular coordination, muscle spasm and other behavior related to withdrawal. Conclusions: Ethanol dependence can be successfully developed in Swiss albino mice in 14 days.
\end{abstract}

Keywords: Ethanol dependence, Swiss albino mice

\section{INTRODUCTION}

The state of being enslaved to a habit or practice or something that is psychological or physically habit forming called addiction. In 2012 global prevalence rates of disorders due to consumption alcohol among adults were estimated to range from $0 \%$ to $16 \%$ and $5.9 \%$ of all global deaths were attribute to alcohol consumption. ${ }^{1}$ World Health Organization (WHO) reported that worldwide 3.3 million people died due to alcohol addiction in $2012-13$ and $11 \%$ of the population in India indulged in heavy drinking in $2014 .^{2}$ Effects of alcohol addiction have negative impact upon marriage life, family life, education, employment, health and wellbeing, personality, financial issues, law and order. ${ }^{3}$
Studying alcohol dependence in humans involved many ethical issues and experimental difficulties. Hence nonhuman animal experimental model has been used for a research on the topic of alcohol intoxication and dependence. Ethanol dependence has been preferred to develop in genetically modified strain of mice, C-57BL/6 which has a natural inclination to consume and develop addiction for alcohol. ${ }^{4}$ But studying addiction in this special strain requires top end experimental facilities and financial aids. To overcome these issues researcher made efforts to develop ethanol dependence animal model to study ethanol dependence in Swiss albino mice. Thus, present article reports the methodology to develop model of dependence in Swiss albino mice. 
There were 12 Swiss albino mice (Number of animals have been used minimum of 6 per group in the final experiments to derive statistically meaningful inference.) and $20 \%$ Ethanol.

\section{Instruments $^{6,7}$}

- $\quad$ Elevated plus maze (EPM)

- Rota rod Apparatus

- Acto-photometer

\section{METHODS}

Swiss albino mice of 6-8 weeks (20-30gms) were subjected to training on Rota rod for three days. 12 animals which can complete the training on Rota rod without fall on 20 RPM were selected for the study. The animals were randomly allotted in two groups having six animals in each group.

All the animals were housed in metabolic cage and provided with Ad libitum. The animals of control group have access to water only whereas the animals of other group were provided with two bottles, one containing $20 \%$ ethanol and other contains water. The $20 \%$ ethanol was provided intermittently with the gap of 24 hours (every alternate day). Initially it was noted that the animals were reluctant to consume ethanol, may be due to the bitter taste of alcohol. To overcome this, sugar $(3 \mathrm{gm} / 100 \mathrm{ml})$ was added to ethanol. To avoid experimental bias same amount of sugar was added to water provided to both the groups. With this modification the animals started consuming ethanol.

In the initial three days the animals were provided with continues access to ethanol without any abstinence to make them habituated with the ethanol consumption. In the later days of experiment schedule was maintained as intermittent access with $24 \mathrm{hrs}$ abstinence till 14 days. Hence the alcohol was provided on Monday, Wednesday and Friday and the abstinence of alcohol was on Tuesday, Thursday Saturday and Sunday in the same week. Intermittent and daily alcohol and water intake was noted respectively. The confirmation of addiction was done with the withdrawal symptoms in the form of anxiety with EPM and muscular in coordination with Rota rod after 24 and $48 \mathrm{hrs}$ from the abstinence of alcohol. The anxiety threshold of the animals was assessed on Day 0,7 and 14 on EPM. The tremors due to withdrawal were assessed on muscular coordination on Rota rod with latency in fall of animals on Day 0, 7 and 14. Animals were subjected to Actophotometer to measure loco motor activity on Day 0 , 7 and 14.

\section{RESULTS}

\section{Water and ethanol intake}

Recording of daily water intake readings revealed that, water intake was maintained in the animals of control group (DW-Distilled water), whereas decreased water intake.

Was noted in animals of ethanol groups. The water intake of ethanol group animals showed significant decrease as compared to control group Figure 1.

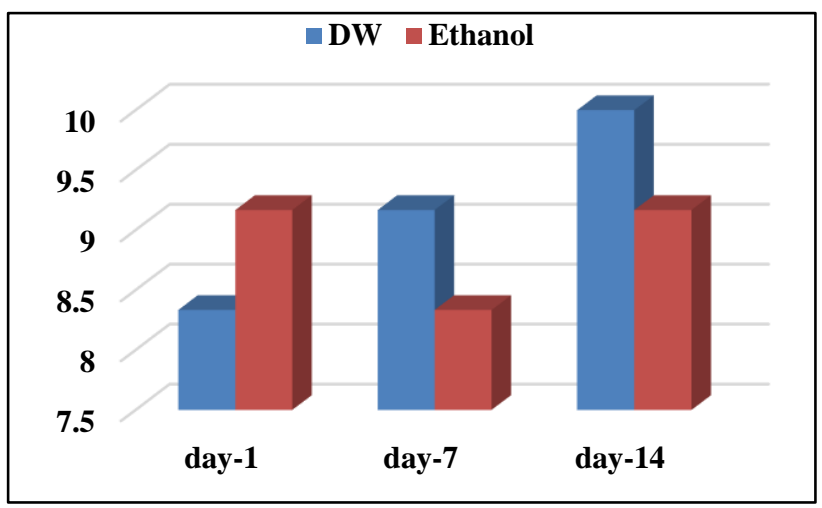
Figure 1: Water intake in DW and ethanol
treated animals.

The alcohol intake showed daily gradual increase, as shown in graph no-2 and the alcohol intake was significantly increased on day 14 as compared to Day 1 indicating increased tolerance for alcohol consumption. Figure 2.

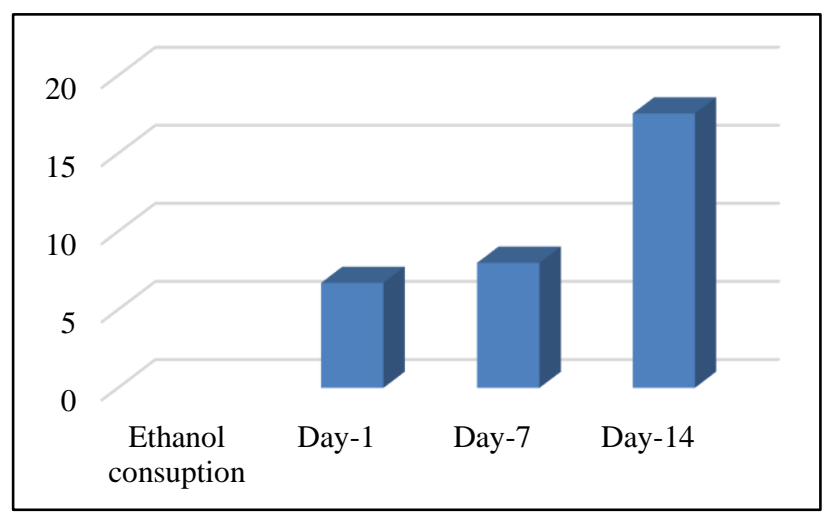

Figure 2: Alcohol intake in negative control group.

\section{Elevated Plus Maze (EPM)}

Anxiety, an essential feature of withdrawal of ethanol has been assessed on the EPM. To assess anxiety developed in the animals due to ethanol withdrawal following criteria was used:

- Number of entries in open arm in 05 min.

- Number of entries in close arm in $05 \mathrm{~min}$.

- Time Spend in open arms of EPM in 05 min.

\section{Number of entries in open ARM}

It has been reported that under the influence of anxiety, the animals avoid entering the open arm and preferred to be in 
closed arm with reduced movements. ${ }^{6}$ Thus, crossing of open arm lines by anxious animals was expected to be less than normal animal. The assessment was done after $48 \mathrm{hrs}$. of abstinence of ethanol.

As shown in Table 1, number of entries of open arm in animals receiving only distilled water was comparable on the Day 7 and 14 and significant reduction was noted on Day 14 as compared to Day 0. However gradual decrease was observed in animals receiving ethanol. The decrease in crossing of arm line in ethanol group is significant on day 7 and 14 as well. Also significant difference in no of entries of open arm line was noted between DW and ethanol groups on day 7 and 14 . $* \mathrm{P}<0.05$, $* * * \mathrm{P}<0.001$ as compared to day- 0 using fried man's test, and @ p $<0.05$, **P $<0.001$ as compared to DW using Mann whitely test (Table 1).

Table 1: Number of entries in open arm of EPM.

\begin{tabular}{|llll|}
\hline Group & Day-0 & Day-7 & Day-14 \\
\hline $\begin{array}{l}\text { DW } \\
\text { (Control) }\end{array}$ & $5.5(4-15)$ & $4(0-13)$ & $2.5(0-7)^{*}$ \\
\hline Ethanol & $13(1-20)$ & $0(0-5)^{* * * @ @ ~}$ & $\begin{array}{l}0 \\
(0-2)^{* * *} @ @\end{array}$ \\
\hline
\end{tabular}

\section{Number of entries in close ARM}

In anxiety, rodents prefer to be in their natural habitat i.e. dark place of closed arm and avoid entering open arm. In the experiment, both the groups showed comparative decrease in no. of entries in open arm when compared with day 0 and day 14. But the decrease in entries of animals of DW treated group was non-significant on day 7 and 14 as compared to baseline entries, however the decrease is significant in ethanol treated animals as compared to baseline no. of crossing in closed arm. Besides the no of entries by ethanol treated animals showed significant reduction as compared to DW treated animals. $* * * \mathrm{P}<0.001$ as compared to day- 0 using fried man's test, and @ $\mathrm{p}<0.05$ as compared to DW using Mann whitely test (Table 2).

Table 2: Number of entries in close arm of EPM.

\begin{tabular}{|llll|}
\hline Group & Day-0 & Day-7 & Day-14 \\
\hline $\begin{array}{l}\text { DW } \\
\text { (Control) }\end{array}$ & $\begin{array}{l}12 \\
(10-13)\end{array}$ & $12(6-18)$ & $9(6-15)$ \\
\hline Ethanol & $11(7-19)$ & $7.5(2-13) * * * @$ & $6(1-11) * * * @$ \\
\hline
\end{tabular}

\section{Time spend in open arms of EPM}

As reported, the animals under the influence of anxiety as a result of ethanol withdrawal do not enter the open arm. Thus, reduction in time spend in open arm is a sign of development of anxiety. As shown in graph, time spent in open arm was not altered significantly on day 7 and 14 in DW group. Whereas, time spent in open arm was significantly decreased on day 7 and 14 in ethanol treated animals. This reduction in time spent is significant as well when compared with DW treated animals. *** $\mathrm{p}<0.001$ as compared to day-0 using friedman's test and @@ $@<<0.01$, @@@ $\mathrm{p}<0.001$ as compared to DW using mann whithey test (Table 3).

Table 3: Time spend in open arms of EPM.

\begin{tabular}{|llll|}
\hline Group & Day-0 & Day-7 & Day-14 \\
\hline DW & 0.165 & 0.215 & 0.215 \\
(Control) & $(0.1-3.04)$ & $(0.08-2.42)$ & $(0.08-1.15)$ \\
\hline \multirow{2}{*}{ Ethanol } & 2.23 & 0.01 & 0 \\
& $(0-3.56)$ & $(0-0.5) @$ @** & $(0-0.15) @ @ @ * * *$ \\
\hline
\end{tabular}

\section{Assessment of muscular Inco-ordination and muscle spasms on rota rod}

\section{Number of falls assessment}

With good muscular coordination animals can adopt the accelerated speed of rota rod and adjust them to walk on the accelerated rota rod without fall.

On rota rod almost, no falls were observed in DW treated animals on day 0, 7 and 14. While in ethanol treated group the no. of fall showed significantly increase on day 7 and 14 and the increase in fall on day 14 was significant as compared to DW group animals. $* * * \mathrm{P}<0.001$ as compared to day-0 using Friedman's test and @@@ p<0.001 as compared to DW (Table 4).

Table 4: Number of falls assessment on rota rod.

\begin{tabular}{|llll|}
\hline Group & Day-0 & Day-7 & Day-14 \\
\hline $\begin{array}{l}\text { DW } \\
\text { (Control) }\end{array}$ & $0(0-1)$ & $0(0)$ & $0(0-1)$ \\
\hline Ethanol & $0(0-1)$ & $2(0-4) * * *$ & $3(0-6) * * * @ @ @$ \\
\hline
\end{tabular}

\section{Assessment of loco motor activity on actophotometer}

In Actophotometer the movement of animals was counted by cutting of the horizontal light beams. Actophotometer readings revealed that both in control and ethanol treated groups; there was increase in activity on day 7 indicating hyperactivity of animals. The hyperactivity was statistically significant in ethanol treated group. In both groups, there was decrease in activity on day 14 that was statistically significant as compare to day-7. There was no difference observed between the groups. $* * * \mathrm{P}<0.001$ as compared to day- 0 \#\# $\mathrm{p}<0.01$, \#\#\# $\mathrm{p}<0.001$ as compared to using repeated measures annova (Table 5).

Table 5: Loco motor activity on Actophotometer.

\begin{tabular}{|llll|}
\hline Group & Day-0 & Day-7 & Day-14 \\
\hline $\begin{array}{l}\text { DW } \\
\text { (Control) }\end{array}$ & $53 \pm 48.83$ & $552 \pm 56.46$ & $496.67 \pm 76.33 \# \#$ \\
\hline Ethanol & $612.28 \pm 79.03$ & $659.58 \pm 74.96 * * *$ & $592.97 \pm 89.72 \# \# \#$ \\
\hline
\end{tabular}




\section{General behavioral observation of animals}

In general, behavioral observation the animals of ethanol group seems to be inactive in cage and used to lie in one corner of cage with very minimum movements on teasing. Also the posture of animals was not healthy and skin showed blackish white appearance due to pilo erection. Whereas the animals of control group maintain their normal behavior, posture and hair pattern till end of the experiment. Figure 3 and Figure 4.

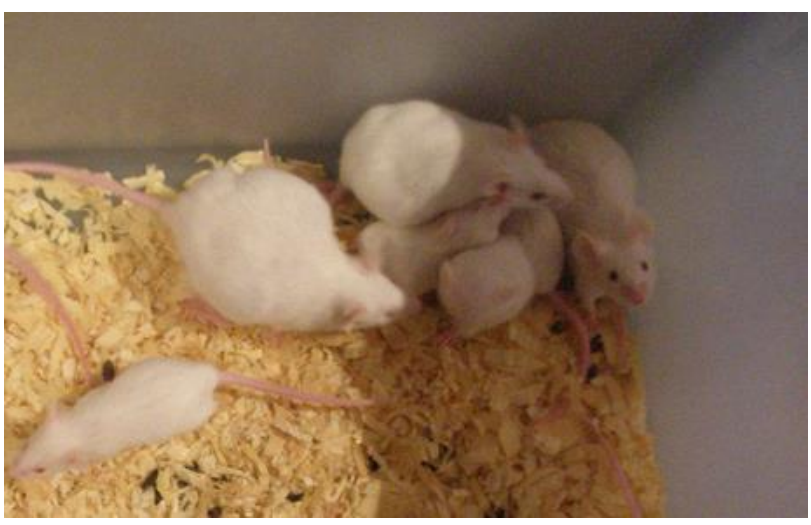

Figure 3: Animal receiving DW.

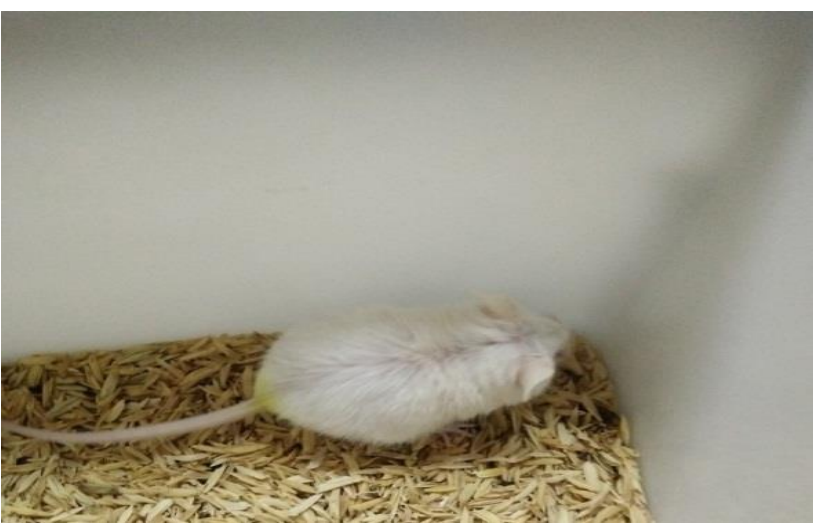

Figure 4: Animal receiving ethanol.

\section{DISCUSSION}

Addiction is a brain disorder characterized by compulsive engagement in rewarding stimuli despite adverse consequences. Long-term ethanol misuse is associated with risk of addiction and physical problems like liver, cardiovascular disease, cancer, nervous system damage and Psychiatric problems such as depression, anxiety, and antisocial personality disorder. ${ }^{1}$ The accepted cardinal symptoms of alcohol dependence in DSM- 5 published by American Psychiatric Association(APA) are craving, anxiety, muscular incoordination, physical dependence and tolerance. ${ }^{8}$

Studying alcoholism in humans involved many ethical issues and experimental difficulties. Hence nonhuman experimental model have been used for a substantial portion of research on the topic of alcohol intoxication and dependence. Various animal models have been used to develop alcohol addiction in rodents.

Developing a model that induces animals to voluntarily consumption of high amounts of alcohol would be an appreciated tool for approximating human alcoholic-like drinking. This pattern can be achieved in models like continues free choice bottle model, intermitted free access and intermitted free access with chronic depravation models. Amongst all the above three models intermittent access seems to be a cardinal feature of many conditions that stimulate drinking large amounts of alcohol required to achieve high blood alcohol concentration to develop addiction and proves a better model to study addiction. Besides, it is also useful to study craving for the alcohol when provided after $24 \mathrm{hrs}$ gap.

In present study free choice two bottle access was availed to mice where one bottle contains alcohol and other water. Advantage of free-choice drinking procedures is that preference of animal for alcohol or water and fluid volumes consumed by the mice can be accurately measured to assess tolerance for alcohol. Thus, it can be claimed that intermittent free access two bottle choice model is appropriate to study important parameters of addiction viz. carvings, preference and tolerance.

Studies on alcohol dependence were reported to be conducted by using C-57BL/6 mice. ${ }^{9,10} \mathrm{C}-57 \mathrm{BL} / 6$ is a common inbred strain of laboratory mouse. It is the most widely used "genetic background" for genetically modified strain having preference for alcohol consumption hence widely used to study addiction. But the strain is delicate to maintain, expensive and requires special environmental conditions and infrastructure whereas, Swiss albino mice is less expensive and also easily available and no need for special care and infrastructure. Hence in present study Swiss albino mice were used to develop model for addiction study.

Craving for substance, anxiety, muscular inco-ordination and tolerance are the known parameters of dependence. ${ }^{11}$ In the present study tolerance for alcohol was assessed by recording daily intake of alcohol. Elevated plus Maze (EPM) was used to assess anxiety, Rota rod for muscular coordination and photo-acto meter for locomotors activity.

Tolerance, preference and cravings were confirm by daily observation and daily reading was taken. Water intake of control group animals was increased as per body weight of animals but negative control group animals have not shown any increase in water intake as per body weight. They showed 3 times increase in alcohol intake on day-14 than day-1. It showed that they preferred alcohol rather than water and also tolerance was increased.

Anxiety may be tested in mice by recording time spent in the open arm of an elevated plus maze. It has been reported that under the influence of anxiety, the animals avoid 
entering the open arm and preferred to be in closed arm with reduced movements. Spending less time in the open arms of the maze indicate greater anxiety-like behavior. Thus, entry in open arm by anxious animals reported to be less than normal animal. The severity of anxiety as a withdrawal symptom, is maximum after $48 \mathrm{hrs}$. of abstinence of ethanol. ${ }^{11}$ Hence, the anxiety threshold was assessed after $48 \mathrm{hrs}$.

It was noted that number of entries in open arm by animals receiving only distilled water was comparable on the Day 7 and 14 and significant reduction in entries in open arm was noted on Day 14 as compared to Day 0. However gradual decrease was observed in animals receiving ethanol. The decrease in open arm entries in ethanol treated group is significant on day 7 and 14 as well. Also significant difference in No. of entries of open arm was noted between DW and ethanol groups on day 7 and 14. In anxiety, rodents prefer to be in their natural habitat i.e. dark place of closed arm and avoid entering open arm. In the experiment, both the groups showed comparative decrease in no. of entries in open arm. But the decrease in entries of animals of DW treated group was non-significant, however the decrease is significant in ethanol treated animals in closed arm. The non-significant decrease in movements of DW group animals may be due to the isolation of animals in metabolic cages. As rodents are social animals and normally kept in group of 4-6 animals in a cage, isolation of animals may have developed anxiety in the animals. Whereas the significant decrease in open arm entries of ethanol group animals was merely due to the effect of withdrawal.

The time spent in open arm was not altered significantly in DW group. Whereas, time spent in open arm was significantly decreased in ethanol treated animals. As reported, the animals under the influence of anxiety as a result of ethanol withdrawal avoid to spent time in open arm. ${ }^{6}$ Thus reduction in time spend in open arm by ethanol treated mice is a sign of development of anxiety. This finding also supports the development of anxiety in the animals. In ethanol withdrawal symptoms tremor is the very important sign, may be assess with movement of animal on Rota rod. ${ }^{11}$ With good muscular coordination animals can adopt the accelerated speed of Rota rod and adjust to walk on the accelerated speed of Rota rod without fall. On Rota rod no falls were observed in DW treated animals whereas in ethanol treated group the number of fall showed significant increase on day 15 . The findings on the rota rod indicate the muscular incoordination due to the tremors as a result of ethanol withdrawal hence evident of development of ethanol dependence in mice.

In actophotometer the movement of animals was counted by cutting of the horizontal light beams. Actophotometer readings revealed that both in control and ethanol treated animals; there was increase in activity on day 7 whereas decrease was observed on day 14 . The readings did not reveal any inference regarding assessment of dependence in animals. Hence it can be concluded that Actophotometer is not useful to confirm dependence.

Behavioral observation like inactiveness of animals in cage with very minimum movements on teasing also confirms the depression due to ethanol dependence.

\section{CONCLUSION}

The research study can be concluded as Ethanol dependence can be successfully developed in Swiss albino mice in 14 days.

\section{Funding: No funding sources \\ Conflict of interest: None declared \\ Ethical approval: Not required}

\section{REFERENCES}

1. World Health Organization. Global status report on alcohol and health, 2014: XIV ed. Available at: https://books.google.co.in/books?hl=en\&lr=\&id=Hb QXDAAAQBAJ\&oi $=$ fnd $\&$ pg $=$ PR $2 \& d q=$ World + Hea lth+Organization.+Global+status+report+on+alcohol + and +health, $+2014:+$ XIV\&ots=PbpEHkQ0zI\&sig=U tNWKCmir917EUtOXMrPvzbm_Mg\#v=onepage \&q $=$ World $\% 20$ Health $\% 20$ Organization.\%20Global\%20 status\%20report\%20on\%20alcohol\%20and\%20healt h\%2C\%202014\%3A\%20XIV\&f=false. Accessed 18 January 2018.

2. WHO Report-2014. Alcohol consumption in India on the rise. Available at: https://www.midday.com/articles/alcohol-consumption-in-india-onthe-rise-who-report/15299173 accessed 18 January 2018.

3. Social Effects of an Addiction - Drug Addiction; 2018. Available at: http://www.medic8.com/drugaddiction/social-effects. Accessed 18 January 2018

4. Jadhav KS, Marathe PA. Evaluation of potassium clavulanate on ethanol consumption and decision making in the model of ethanol dependence in mice. J of Pharmacol \& Pharmacothe. 2014 Oct;5(4):250.

5. Sebastien C, Dorit R, Segev B, Intermittent ethanol access schedule in rats as a preclinical model of alcohol abuse, Alcohol. 2014 May;48(3):243-52.

6. Gerhard VH. Med eds. Drug Discovery and Evaluation Pharmacological Assays E.2.4.4 Elevated plus maze test. $2^{\text {nd }}$ Ed. ISBN 3-540-42396-6; 2002: 434.

7. Jayasree T, Naveen A, Chandrasekhar N, Sunil M, Kishan PV, Jagan RN. Evaluation of muscle relaxant activity of aqueous extract of sapindustrifoliatus (pericarp) in swiss albino mice. J Chem Pharm Res. 2012;4(4):1960-4.

8. American Psychiatric Association, Diagnostic and Statistical Manual of Mental Disorders, Fourth Edition. Washington, D.C.: The Association, 1994.

9. Herz A. Endogenous opioid systems and alcohol addiction. Psychopharmacology. 1997 Jul 1;129(2):99-111. 
10. Igor P, John C, Crabbe A Novel Method to Assess Initial Sensitivity and Acute Functional Tolerance to Hypnotic Effects of Ethanol Journal of Pharmacology and Experimental Therapeutics July 2002;302(1):25763.
11. Alcohol withdrawal syndrome, 2018. Available at: https://en.wikipedia.org/wiki/Alcohol_withdrawal_sy ndrome. Accessed 25 April 2018.

Cite this article as: Chotai TM, Kapgate SM.

Standardization of ethanol addiction model in Swiss albino Mice. Int J Basic Clin Pharmacol

2018;7:1365-70 